\title{
REVIEW
}

\section{Recommendations for enhancing psychosocial support of NICU parents through staff education and support}

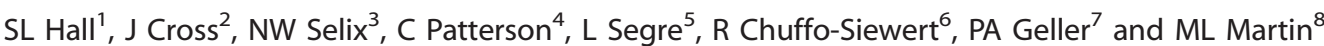

Providing psychosocial support to parents whose infants are hospitalized in the neonatal intensive care unit (NICU) can improve parents' functioning as well as their relationships with their babies. Yet, few NICUs offer staff education that teaches optimal methods of communication with parents in distress. Limited staff education in how to best provide psychosocial support to families is one factor that may render those who work in the NICU at risk for burnout, compassion fatigue and secondary traumatic stress syndrome. Staff who develop burnout may have further reduced ability to provide effective support to parents and babies. Recommendations for providing NICU staff with education and support are discussed. The goal is to deliver care that exemplifies the belief that providing psychosocial care and support to the family is equal in importance to providing medical care and developmental support to the baby.

Journal of Perinatology (2015) 35, S29-S36; doi:10.1038/jp.2015.147

\section{RATIONALE}

The manner in which neonatal intensive care unit (NICU) physicians, nurses and other staff interact with parents greatly influences parents' perceptions long after their baby has been discharged from the NICU. ${ }^{1}$ Although attempts are made to educate NICU staff, many feel less than fully prepared to respond to parents' distress, meet their psychosocial needs and interact with them in ways that will enhance their coping both during their NICU stay and postdischarge. ${ }^{2}$ Moreover, NICU staff are themselves at risk for the adverse physical and emotional consequences of providing care in one of the hospital's most stressful work areas. If staff are not sufficiently made aware of how to manage their own work stress, the consequences can include burnout, compassion fatigue, secondary traumatic stress syndrome and/or post-traumatic stress disorder. Staff may then become emotionally guarded or depleted, and unable to offer supportive care to emotionally vulnerable NICU parents.

Burnout syndrome was defined in 1988 as a 'state of physical, emotional and mental exhaustion caused by long-term involvement in emotionally demanding situations.'. ${ }^{3}$ Burnout stems primarily from conflict within the work setting, such as unhappiness over work conditions, salary or disagreements with co-workers or supervisors. ${ }^{4}$ It is reported that as many as $40 \%$ of hospital nurses exhibit symptoms of burnout, ${ }^{5}$ and rates of burnout by health-care workers $(n=820)$ reported in one review of 44 NICUs ranged from 7.5 to $54.4 \%$, with rates being higher in non-physicians. ${ }^{6}$ Neonatologists are not immune to burnout, though. One study of 110 neonatologists found that $30 \%$ experienced high burnout and another 60 to $65 \%$ were in the 'at-risk' range. ${ }^{7}$ Among the factors associated with burnout in neonatologists are work experience of $<5$ years, believing that living with a physical disability is unworthy and having recurrent death ideation.?

Factors contributing to stress and burnout among NICU nurses fall into three general categories. First, several aspects of the NICU physical and interpersonal work environment can be challenging. Working in physical surroundings often with inadequate lighting and excessive ambient noise, ${ }^{8}$ being overstimulated in the pervasive crisis atmosphere, ${ }^{9}$ experiencing interdisciplinary conflicts ${ }^{7}$ and facing verbal abuse from distressed families can add to levels of stress. ${ }^{10}$ Moreover, staff must manage this work environment for long hours while maintaining vigilance over their patients and promoting a calm environment for families, as well as a professional and caring persona. ${ }^{11}$ Workload issues constitute a second general category of stress, including dealing with excessive and unrealistic patient assignments because of inadequate staffing, ${ }^{10,12-14}$ working mandatory overtime during periods of high census, or, alternatively, being forced to take days off during periods of low census. ${ }^{15}$ Providing patients and families with optimal care creates a third general category of factors. Poor communication skills may contribute to nurses' feelings of inadequacy about their ability to provide necessary emotional support to families. ${ }^{4}$ Ethical dilemmas may create moral distress, such as when nurses are asked to carry out end-of-life orders to which they have a 'conscientious objection'. ${ }^{16,17}$ Staying current with changing practices and technological advances is also challenging. ${ }^{11,13}$

Nurses who report being burned out experience greater difficulties in their personal lives, ${ }^{18}$ a variety of psychological complaints, higher rates of alcohol and drug abuse ${ }^{19-21}$ and compulsive gambling. ${ }^{22}$ Stressed nurses are also prone to experiencing a variety of health problems, including sleeplessness, headaches, muscle tension, ${ }^{13}$ immune dysfunction and

\footnotetext{
${ }^{1}$ Division of Neonatology, St John's Regional Medical Center, Oxnard, CA, USA; ${ }^{2}$ Department of Social Work, Widener University, Chester, PA, USA; ${ }^{3}$ School of Nursing and Health Professions, University of San Francisco, San Francisco, CA, USA; ${ }^{4}$ Children's Hospital of Philadelphia, Philadelphia, PA, USA; ${ }^{5}$ College of Nursing and Department of Psychological and Brain Sciences, University of lowa, lowa City, IA, USA; ${ }^{6}$ Department of Nursing, University of lowa Children's Hospital, lowa City, IA, USA; ${ }^{7}$ Departments of Psychology, Obstetrics/Gynecology and Public Health, Drexel University, Philadelphia, PA, USA and ${ }^{8}$ Department of Nursing, McLeod Regional Medical Center, Florence, SC, USA. Correspondence: Dr SL Hall, Division of Neonatology, St John's Regional Medical Center, 1600 N. Rose Avenue, Oxnard, CA 93030, USA.

E-mail: suehallmd@gmail.com
}

Received 10 September 2015; accepted 23 September 2015 
gastrointestinal or cardiovascular disturbances. ${ }^{23}$ In addition, seasoned nurses with considerable work experience may have increased susceptibility to the cumulative effect of stressful experiences that can also lead to post-traumatic stress disorder. ${ }^{10}$

High rates of burnout among nurses in general are associated with many adverse effects on patient care, including an increase in health-care associated infections, ${ }^{24}$ a decrease in recognition and reporting of errors, ${ }^{25}$ an increase in patient mortality ${ }^{14}$ and a decrease in patient-reported satisfaction. ${ }^{26}$ Hospitals whose nurses have high rates of burnout are more likely to experience increased rates of employee tardiness and absenteeism, ${ }^{19,20}$ as well as high rates of nursing turnover. ${ }^{27}$

Compassion fatigue has been described as a unique form of burnout; the two conditions have overlapping symptoms, including physical, emotional and work-related symptoms. ${ }^{9,28}$ Although staff suffering from burnout are likely to withdraw from interpersonal interactions with patients and families, those with compassion fatigue are likely to become overinvolved and 'try harder' despite feeling emotionally exhausted. ${ }^{28}$

Whether a health-care professional develops burnout and/or compassion fatigue, the result is the same. The provider may not be emotionally available to support the psychological needs of their patients and their patients' family. Reducing staff burnout and compassion fatigue could lead to lower costs in treatment of health-care associated infections and to hiring and training new staff. ${ }^{29}$ Other benefits include the potential to improve employee morale, patient and family satisfaction, ${ }^{4,12}$ and ultimately patient survival. $^{14}$

The purpose of these recommendations is to define standards for education and support of NICU staff that will enable them to feel sufficiently prepared to provide psychosocial care and support to the family.

\section{RECOMMENDATIONS FOR STAFF EDUCATION}

Staff education relating to the psychosocial needs of NICU families and methods of providing support should be provided to all NICU staff. 'All NICU staff' refers to all disciplines that interact with NICU families on any level. Staff education should be provided during orientation and then periodically throughout the course of every year. Education of interdisciplinary groups should promote fruitful discussion and collaborative interaction.

\section{TOPICS FOR STAFF EDUCATION}

Normal responses to infant hospitalization

NICU staff should be made aware of the emotional impact of the NICU experience on parents and the 'normal'/expected responses to this abnormal and often unexpected life-changing event. Of the multiple emotional, psychosocial and situational stressors parents may experience, those related to their infant's precarious health status are usually paramount. Parents may also experience a variety of unexpected and traumatic emotions related to their pregnancy and birth experiences leading up to NICU admission. Additional psychosocial and interpersonal stressors may include financial hardship, transportation and lodging challenges, and the strains of balancing family, home and work life. ${ }^{30,31}$ These stressors bring forth a variety of emotional responses that parents do not expect but which commonly occur; these may include shock, fear, guilt, anger, lack of control and jealousy of parents with healthier babies. Parents may also resent NICU staff who oftentimes spend more time with their babies than parents are able to. Furthermore, parents' emotions render them less able to concentrate and to make decisions, compounding an already stressful situation. Given this, one important goal of the NICU staff should be to help parents normalize their common emotional responses. $^{32}$

Perinatal mood and anxiety disorders in NICU parents

The cumulative stresses faced by NICU parents confer higher risk for perinatal mood and anxiety disorders compared with parents of healthy, full-term infants. A comprehensive curriculum about perinatal mood and anxiety disorders experienced by NICU parents should incorporate the following topics: (a) information about depression, ${ }^{33-38}$ anxiety ${ }^{34,37}$ and post-traumatic stress disorder ${ }^{35,39,40}$ in NICU mothers and fathers, including epidemiology and risk factors, ${ }^{41}$ adverse effects of these conditions on parent-infant attachment ${ }^{42,43}$ and the physical, cognitive and emotional development of infants; ${ }^{32,44,45}$ (b) methods for screening for perinatal mood and anxiety disorders (see 'Recommendations for mental health professionals in the NICU', this issue); and (c) a review of efficacious treatments offered for parents in the NICU. ${ }^{46-48}$

Family-centered developmental care

The American Academy of Pediatrics has called upon pediatric staff to embrace families as true collaborators in the care of their children. Parents should function as integral members of the health-care team and their views should be incorporated into care plans. ${ }^{49,50}$ Staff should be educated about methods for improving and expanding implementation of family-centered developmental care in the NICU, as found in 'Recommendations for involving the family in developmental care of the NICU baby', this issue.

\section{Culturally effective care}

An important component of staff education involves increasing awareness of how to provide care that is culturally effective, ${ }^{51,52}$ as endorsed by the American Academy of Pediatrics. ${ }^{53}$ Respect for diversity regarding racial, ethnic, spiritual, educational, geographic and socioeconomic backgrounds, cultural and linguistic traditions, and care preferences comprises one of the general principles of family-centered care. ${ }^{49,50}$ Improving the quality of provider communication may be key in increasing the extent to which minority populations are involved in family-centered care. ${ }^{54}$ To achieve cultural sensitivity, staff should be encouraged to undergo an educational process that involves gaining self-awareness, learning to appreciate the differences and value of cultural practices other than one's own and exhibiting behavioral flexibility. ${ }^{55,56}$

Differences in preferences for care and satisfaction with care have been documented among parents of diverse cultural backgrounds in pediatric settings. ${ }^{57-59}$ Developing trust between families and their medical providers is an important element in communication and may vary among racial groups. Tang et al. ${ }^{60}$ reported that although African-American parents trusted their individual health-care providers in the NICU to the same degree as white parents, a greater proportion of African-American parents mistrusted the medical profession in general.

Parents who are recent immigrants, speak English as a second language, have low educational levels or have lower incomes are more likely to have low health literacy skills. ${ }^{61}$ Parents with any of these attributes are an especially vulnerable population and need information delivered in an understandable way. Methods to enhance parental understanding include providing written materials using terms that are easy to comprehend in their native language, asking parents to teach back what has been taught ${ }^{62}$ and providing opportunities to ask questions in an unhurried manner using an interpreter as needed. Information should also be provided within a cultural framework. For example, in some cultures, a family member other than the parents may make all 
health-care decisions. For this reason, parents should be asked whom they prefer to be involved in making health-care decisions.

To facilitate optimal communication, hospital staff who interact with non-English-speaking families should use trained, nonvolunteer interpreters. Even when interpreters are used, cultural differences can still contribute to difficulties in communication with families. $^{63,64}$ However, interpreters may be able to help the medical team understand the influence of cultural norms. ${ }^{52}$

\section{Self-care}

Education should cover elements of self-care for staff so NICUs can become proactive in preventing and minimizing burnout and compassion fatigue, ${ }^{16}$ including: (a) education on management of work stresses, ${ }^{28}$ which include communication skills, techniques for boundary setting, ethics and knowledge of family system dynamics; (b) maintenance of work-life balance by giving attention to adequate nutrition, hydration, sleep, exercise and pleasurable activities that promote overall health and well-being ${ }^{28}$ and (c) management of life skills, including time management, budgetary management and stress reduction. ${ }^{13,28}$

\section{Competent communication}

Research has shown that a mother's perception of the support she received from her nurse correlates with her level of depression. ${ }^{36}$ Specifically, a one point decrease of a mother's rating on the Nurse Parent Support Tool resulted in a $6 \%$ increased risk for depression. Equipping nurses with advanced communication skills is especially important as parents view nurses as a more frequent source of information ${ }^{65}$ and support ${ }^{1}$ than neonatologists. Multiple studies have shown that NICU parents have identified a need for improved staff-parent communication., ${ }^{1,66-68}$

Although staff frequently speak with NICU parents, their efforts to communicate about the infant's status do not always lead to parental understanding. De Wit et al. ${ }^{69}$ compared mothers' understanding of their NICU infant's illness to clinicians' perceptions. Although most mothers understood at least one aspect of their infant's diagnosis, mothers often believed that their infant was less sick than the clinician did. This discrepancy may have been the result of parents' unrealistically optimistic expectations. Teen-aged parents of NICU babies may not fully grasp the information being communicated to them, often underestimating the critical nature of their infant's illness, in part because they may be reluctant to ask providers to clarify technical language. ${ }^{70}$

Each institution should have a communication curriculum that includes a number of topics. First, the curriculum should teach staff how to provide information about the baby's diagnoses and expected course using simple, straightforward language void of medical jargon and presented in a warm, sympathetic manner. ${ }^{69}$ Staff can benefit from a number of suggestions as to how families would like to receive 'bad news'. Instruction should include when and how to approach parents, and how providers should pace themselves during these discussions, speaking from an empathetic perspective and staying away from using medical jargon. ${ }^{52,71-76}$ Second, staff can learn how to interact with parents from the perspective of an expert coach and facilitator, ${ }^{77}$ so that parents can become competent in their baby's care. This coaching can be carried out by using a teach-back method. ${ }^{62}$ Third, instruction should include segments covering how to provide psychosocial support to families in crisis, which starts by engaging in active listening to a family's concerns and fears. ${ }^{10,72}$ This may require skills in conflict resolution ${ }^{10}$ or the provision of support to parents during palliative and bereavement care. ${ }^{78,79}$ Finally, the program should ensure that the health-care team knows how to involve families in making care decisions, ${ }^{80}$ including decisions about whether or not to resuscitate extremely immature neonates. ${ }^{81}$

\section{MODELS OF COMMUNICATION TRAINING}

A variety of models for communication training of both NICU physicians ${ }^{73,82-88}$ and nurses ${ }^{89}$ exist. Each NICU should tailor their efforts to the size, composition and needs of their staff, balanced with the resources available to the hospital. Within these models, personalizing information for specific patients is likely to provide the greatest benefit. $^{74}$ Most curricula combine practical and theoretical aspects to achieve these goals. ${ }^{90}$

Providing increased and more sensitive communication Janvier et al. ${ }^{76}$ suggested that parental dissatisfaction in the NICU was usually the result of inadequate communication leading to the family's perception that their needs were not met, rather than inadequate medical care. This report noted that parents would like health-care professionals to introduce themselves, call their baby by name and not diagnosis, speak in lay person's language (i.e., not use medical jargon), speak with one voice, know their baby, acknowledge their parental role and not label them as a difficult parent.

Audiotaping family conferences is a strategy that can help highlight and reiterate key issues for parents, who may have trouble processing information given to them during NICU admission. Koh and Jarvis ${ }^{91}$ found that the taped conversations between parents and neonatologists helped parents recall specifics of their infant's condition and how to support their infant. Penticuff et al. ${ }^{92}$ familiarized parents with an Infant Progress Chart and used parent-provider care planning conferences to improve collaboration in the NICU. This approach increased parents' understanding of their baby's care, especially among young, low income, minority mothers. Johnston et al. ${ }^{93}$ reported improved parents' satisfaction as a result of: (a) familiarizing a family with the NICU environment, its care philosophies and team members, (b) establishing contact between the family and members of the NICU team before the birth of the infant and (c) creating opportunities to dialog about an infant's condition and the family's concerns.

To increase communication between the principal medical provider (PMP) in the NICU and parents, Weiss et al. ${ }^{94}$ focused on maximizing providers' engagement, availability, understanding, reciprocity and empathy. This process was accomplished by providing a short education module for PMPs; giving the parents a contact card with the PMP's name, job description and contact information; and displaying a large poster of the faces, names and titles of the PMPs at the parents' entrance to the NICU. A careful introduction of the program and the PMP, along with maintenance of weekly contacts and use of interpreter services, were deemed essential to the success of the program.

Many parents desire to attend family-centered medical rounds. ${ }^{68}$ Voos et al. $^{95}$ reported that these rounds increased parental satisfaction with their baby's health-care providers compared with attending traditional rounds. Parents can also be involved in nursing change-of-shift report to further enhance bidirectional communication. ${ }^{50}$

\section{Simulation training and interactive workshops}

Simulation training (especially using 'standardized patients' or 'role-playing') is an effective method of staff education. ${ }^{84,86,96}$ Simulation provides a 'safe' environment in which participants can receive non-judgmental, supportive feedback from colleagues, enhance existing skills and develop new skills. ${ }^{97}$ The use of standardized patients has been an useful tool given the realistic, interactive nature of this technique. ${ }^{96}$ Scripts can be written to simulate emergencies, routine patient care or communication interactions that require specific techniques, such as delivering 'bad news'. After the simulation, participants can review videotapes of their interactions and perform a self-assessment. 
Observers can also give feedback. Although most educators have moved toward simulation training, less expensive alternatives such as role-playing may be equally effective. ${ }^{98}$

A training format of longer duration is the Program to Enhance Relational and Communication Skills-Neonatal Intensive Care Unit (PERCS-NICU). ${ }^{87}$ This program consists of 10 to 15 workshops for interdisciplinary health-care providers. Facilitators included a neonatologist, a psychosocial professional and a family faculty member. The PERCS-NICU program was shown to improve communication and relational skills, increase confidence and reduce anxiety for NICU providers. ${ }^{87}$

The Neonatal Critical Care Communication ${ }^{84}$ was developed to teach advanced communication skills to NICU fellows and neonatal nurse practitioners. This evidence-based training involved didactic sessions, small-group role-playing with actors and reflective exercises during a 3-day retreat away from the hospital. The program increased clinicians' self-perceived competence to face common communication challenges; however, no objective measures of improvement were used.

\section{Listening visits}

Listening visits (LVs), a nurse-delivered treatment for maternal depression, is a specific model of communication that can be provided within the NICU as an extension of family-centered care. $^{99,100}$ The LV intervention is based on the idea that providing a woman with the opportunity to express her feelings with consistent social support reduces depressive symptoms. Each LV session lasts $\sim 1 \mathrm{~h}$ and combines active listening with problem solving. A preliminary open trial has shown promising results for the effectiveness of LV within the NICU. Most NICU mothers who were eligible to receive LV from an NICU nurse opted to receive this intervention; LV recipients had significant improvements in mood. ${ }^{99}$ These results suggest that LV delivered at the infantpoint-of-care by an NICU nurse are both an acceptable and effective treatment option to at-risk mothers who are not likely to access other forms of mental health care. The training for nurses to engage in the LV intervention with NICU mothers is easily taught. $^{99,101}$

\section{IMPLEMENTING STAFF EDUCATION: POTENTIAL BARRIERS AND FUTURE DIRECTION}

Numerous barriers to the implementation of staff education programs may be encountered. Creating time for staff to attend educational programs is challenging, given long shifts, busy patient assignments and staff fatigue. Cost may also be a factor, both in creating and delivering educational programs, as well as in compensating staff for their time. Professionals who hold the narrow view that their caregiving responsibilities extend primarily to provision of medical care may not feel comfortable expanding their role to providing psychosocial care. These staff may not perceive the parents of babies they care for as their 'patients'. Staff who feel overwhelmed by the acuity of the babies in their care may also feel that their responsibilities for medical care inhibit their ability to provide psychosocial support.

To overcome the barriers, the interdisciplinary leadership team must endorse the importance of staff education and be committed to its development. The NICU culture must realize the importance of psychoeducation concurrent with medical education. Staff education should be offered on both day and night shifts, and continuing education credits should be awarded to attendees. Ongoing education of staff should be fully integrated into a variety of other platforms including case conferences, case debriefings, morbidity and mortality conferences, $^{72}$ ethics rounds, daily family-centered medical rounds, and so on. Administrators must consider the many benefits of providing staff education in communication skills; some of these include increased parent satisfaction, improvement in families' functioning and less staff burnout/staff turnover.

Further research to develop improved strategies to enhance competence in communication skills, as well as to measure the effectiveness of the various communication skills training programs, is warranted. $82,97,102,103$

\section{RECOMMENDATIONS FOR STAFF SUPPORT}

Psychologists, social workers and other mental health professionals

Mental health professional (MHPs) who work in NICUs should provide support to staff as well as to families. ${ }^{104-106}$ Support may be accomplished through acting as a liaison between staff and families, and/or through discussions of family dynamics and family/staff interactions at a variety of settings. ${ }^{52}$ MHPs can also help staff become aware of signs of compassion fatigue, burnout moral distress and other more concerning problems staff might experience related to the trauma of providing intensive care. MHPs can provide NICU staff with guidance and referral to on-site and community-based resources to address their mental health needs.

\section{Pastoral care staff}

NICUs should have a dedicated pastoral care person integrated within the care team. ${ }^{107}$ In addition to providing spiritual support to the families of patients, pastoral care staff should be available to support NICU staff in becoming more aware of their own values, ${ }^{108}$ particularly how their religious background and spiritual perspective may affect their interactions with patients. Pastoral care staff can participate in ethical consultations and decisionmaking, and help to address moral distress. ${ }^{109}$

\section{Nurses}

Nurses should support each other through mentoring relationships, ${ }^{28,110,111}$ team building activities ${ }^{10}$ and nursing recognition activities. ${ }^{3}$ Individual nurses and administrative leaders share the responsibility in preventing nurse burnout ${ }^{13}$ and compassion fatigue. Many of the factors associated with these conditions can be changed through a hospital's commitment to reduce them.

Hospital or NICU-specific ethics committee and palliative care teams

An ethics committee should be available to help staff minimize the occurrence of moral distress, burnout and compassion fatigue. ${ }^{112}$ The ethics committee can give guidance to help staff and families negotiate end-of-life decision-making and determine guidelines for infant viability. ${ }^{113,114}$ NICU staff should receive both initial and ongoing training and education in ethics, particularly related to engaging in shared decision-making with parents around withholding of life-sustaining treatment, ${ }^{81}$ withdrawal of life-sustaining treatment, end-of-life care ${ }^{115}$ and palliative care. ${ }^{116}$ Lack of formal training in palliative care may render NICU staff reluctant to become involved. Although NICU staff may feel confident in their palliative care delivery even without formal training, staff (and families) benefit from the guidance and support of palliative care teams in their discussions and interactions with families. ${ }^{116}$

\section{METHODS OF STAFF SUPPORT}

Debriefing sessions

A debriefing session is an interdisciplinary meeting that can facilitate processing of emotions and provide support for NICU staff, especially when it is held shortly after a difficult case, 
including those that are ethically and morally challenging, or the death of a patient. ${ }^{4,52}$ Sessions review the case and focus on the aspects of both medical and psychosocial care that could have been improved. Some staff members may prefer one-on-one debriefing from an NICU MHP staff, rather than meeting as a group. Because debriefing sessions can elicit strong and sometimes opposing emotions and views, it is important to have a qualified professional leading the discussion. ${ }^{117}$

There are potential barriers to conducting debriefing sessions. Staff who want to attend may not be working when the sessions are held, or attendance may be limited by work assignments. Some may not choose to attend the session without encouragement, and some who do attend may not want to talk about tough issues. To remove access barriers and facilitate staff attendance, nurse managers should try to arrange patient assignment coverage and/or compensate staff who want to attend debriefing sessions. ${ }^{117}$ Nursing and medical leadership should support debriefing sessions to ensure that everyone has time to process their activities and feelings. Leadership may need to personally invite staff to attend to make sure that all are supported.

Encouraging participation in bereavement interventions

Offering staff the opportunity to participate in bereavement interventions during and after provision of end-of-life care, such as conducting remembrance ceremonies and giving time to attend funerals, ${ }^{4}$ can help them process the grief experienced when a patient dies.

\section{Optimizing the physical environment}

Ensuring an optimal physical environment, including one that conforms to standards for noise and lighting, ${ }^{118}$ and one in which communication and safety concerns of nursing staff are adequately addressed, will facilitate staff satisfaction. Although redesign of NICUs with some or all single family rooms has been driven largely by the desire to support optimal infant development, this transition has also been associated with reported decreases in job stress and anxiety among nurses. ${ }^{119-122}$ Factors contributing to decreased stress include decreased noise levels, ${ }^{122,123}$ reduced crowding ${ }^{122}$ and a perception of the work environment as being more private, less distracting, less hectic and less fatiguing. ${ }^{119}$ In addition, nurses working in single family room NICUs are less likely to experience burnout and more likely to rank quality of care higher. ${ }^{124}$ These attributes of single family room NICUs may make it easier for hospitals to recruit and retain their workforces. ${ }^{125}$ There are, however, potential drawbacks to the single family rooms. Staff ${ }^{119,126}$ and families ${ }^{127}$ may feel isolated, and staffing and nurse-to-nurse communication can become more challenging. ${ }^{123}$ Importantly, Pineda et al. ${ }^{128}$ found that infants cared for in single family rooms had lower language scores and a trend toward lower motor scores at age 2 years, suggesting a potential adverse impact of more limited sensory stimulation. Further research is needed to determine the optimal type of NICU design that will best meet the needs of staff, families and babies.

Ensuring support from nursing, medical and hospital administration

Focusing on staff training alone is insufficient, as it neglects employment practices and issues of management style that contribute to burnout. ${ }^{129}$ Making sure that channels of communication between nursing staff and their supervisors are clear will provide nurses with an outlet to access support. Nursing administrators can also provide support to nurses through attention to best practices in staffing, including ensuring adequate staff $^{10,130}$ and provision of breaks, as well as days off and orientation and mentoring of new nurses. ${ }^{28,110}$ Nurses may also derive support from the institution of 'no-tolerance' policies for families who become verbally or physically threatening. ${ }^{10}$

Medical administrators should be cognizant of work force issues that impact physician burnout and should ensure adequate staffing of the NICU's medical team. Allowing physicians to exercise control over their hours and schedule is an important predictor of lower rates of physician burnout. ${ }^{131}$ The importance of physicians collaborating with other members of the NICU team should be emphasized and promoted. ${ }^{129}$

Hospitals should provide support for staff who develop posttraumatic stress disorder or other psychological distress as needed, ${ }^{10}$ either through personal therapy, support groups, onsite counseling via employee assistance programs, pastoral care ${ }^{28}$ or other professional resources within the hospital. ${ }^{4}$ Employee wellness programs may also provide additional support through nutrition, art therapy, massage, group exercise and/or stress reduction classes. ${ }^{132}$

\section{SUMMARY}

NICU staff work in a stressful environment and must balance caring for fragile, high-risk babies with providing psychosocial support to the babies' families. Educating all staff and providing them with tools to better understand parents' needs, to provide culturally effective family-centered care and to enhance their communication skills can both decrease parents' risks to experience perinatal mood and anxiety disorders and increase parents' satisfaction with their NICU experience. Educating staff about self-care and also providing them with support in a variety of ways can help to minimize the occurrence of burnout, compassion fatigue and secondary traumatic stress disorder. When staff are better prepared to handle the challenges of supporting NICU families in distress, then staff, babies and families benefit.

\section{CONFLICT OF INTEREST}

SL Hall has a consulting agreement with the Wellness Network, but this organization had no input or editing rights to the content included in the recommendations. The remaining authors declare no conflicts of interest.

\section{ACKNOWLEDGEMENTS}

This article has been supported by grants and contributions from: the Wellness Network, Prolacta Bioscience, Division of Neonatology at Loma Linda University School of Medicine, Brenau University, NICU Parent Support at Mercy Hospital in St Louis, MO, Hand to Hold, Preemie Parent Alliance, Zoe Rose Memorial Foundation, the Rosemary Kennedy Trust and Eden's Garden. Many thanks to other participants from the National Perinatal Association Workgroup on Psychosocial Support of NICU Parents for their contributions to this work, including Amy Baughcum, Andrea Schwartz Goodman, Becky Hatfield, Pec Indman, Lauren Leslie, Rachel Ponzek, Laney Poye and Anne Santa-Donato.

\section{REFERENCES}

1 Wigert $\mathrm{H}$, Blom $\mathrm{M}$, Bry K. Parents experiences of communication with neonatal intensive care unit staff: an interview study. BMC Pediatr [Internet] 2014; 14(1): 304; available at: http://www.biomedcentral.com/1471-2431/14/304 (date last accessed 15 April 2015).

2 Placencia F, McCullough L. Biopsychosocial risks of parental care for high-risk neonates: implications for evidence-based parental counseling. J Perinatol 2012; 32(5): 381-386.

3 Pines A, Aronson E. Career Burnout: Causes and Cures. Free Press: New York, NY, USA, 1988.

4 Boyle D. Countering compassion fatigue: a requisite nursing agenda. Online J Issues Nurs 2011; 16(1); 2. Available at: http://www.nursingworld.org/MainMenuCategories/ ANAMarketplace/ANAPeriodicals/OJIN/TableofContents/Vol-16-2011/No1-Jan-2011/ Countering-Compassion-Fatigue.html (date last accessed 27 May 2014).

5 Aiken L, Clarke S, Sloane D, Sochalski J, Busse R, Clarke H et al. Nurses' reports on hospital care in five countries. Health Aff 2001; 20: 43-53. 
6 Profit J, Sharek P, Amspoker A, Kowalkowski M, Nisbet C, Thomas E et al. Burnout in the NICU setting and its relation to safety culture. BMJ Qual Saf 2014; 10 . 806-813.

7 Bellieni C, Righetti P, Ciampa R. Assessing burnout among neonatologists. J Matern Fetal Neonatal Med 2010; 25(10): 2130-2134.

8 Donchin Y, Seagull F. The hostile environment of the intensive care unit. Curr Opin Crit Care 2002; 8(4): 316-320.

9 Marshall R, Kasman C. Burnout in the neonatal intensive care unit. Pediatrics 1980; 65(6): 1161-1165

10 Czaja A, Moss M, Mealer M. Symptoms of post-traumatic stress disorder among pediatric acute care nurses. J Pediatr Nurs 2012; 27(4): 357-365.

11 Cricco-Lizza R. The need to nurse the nurse: emotional labor in neonatal intensive care. Qual Health Res 2014; 24(5): 615-628.

12 Vahey D, Aiken L, Sloane D, Clarke S, Vargas D. Nurse burnout and patient satisfaction. Med Care 2004; 42(2, Suppl.): 1157-1166.

13 Braithwaite M. Nurse burnout and stress in the NICU. Adv Neonatal Care 2008; 8 (6): 34-37.

14 Aiken L, Clarke S, Sloane D, Sochalski J, Silber J. Hospital nurse staffing and patient mortality, nurse burnout and job dissatisfaction. JAMA 2002; 288(16): 1987-1993.

15 Garrett $C$. The effect of nurse staffing patterns on medical errors and nurse burnout. AORN J 2008; 87(6): 1191-1192.

16 Meadors $\mathrm{P}$, Lamson A. Compassion fatigue and secondary traumatization: provider self care on intensive care units for children. J Pediatr Health Care 2008; 22 (1): 24-34.

17 Catlin A, Armino C, Volat D, Vale E, Hadley MA, Gong W. Conscientious objection: a potential neonatal nursing response to care orders that cause suffering at the end of life? Study of a concept. Neonatal Netw 2008; 27(2): 101; available from IngentaConnect Journals http://www.ingentaconnect.com/ content/springer/jnn/2008/00000027/00000002/art00005 (last accessed 31 March 2015).

18 Mealer M, Burnham E, Goode C, Rothbaum B, Moss M. The prevalence and impact of posttraumatic stress disorder and burnout syndrome in nurses. Depress Anxiety 2009; 26(12): 1118-1126.

19 Duquette A, Kerouac S, Sandhu B, Beaudet L. Factors related to nursing burnout: a review of empirical knowledge. Issues Ment Health Nurs 1994; 15: 337-358.

20 Parker P, Kulik J. Burnout, self- and supervisor-rated job performance, and absenteeism among nurses. J Behav Med 1995; 18(6): 581-599.

21 Robinson S, Roth S, Keim J, Levenson M, Flentje J, Bashor K. Nurse burnout: work related and demographic factors as culprits. Res Nurs Health 1991; 14(3): 223-238.

22 Espelande K. Overcoming burnout: how to revitalize your career. J Contin Educ Nurse 2006; 37(4): 178-184.

23 Eriksson U, Starrin B, Janson S. Long-term sickness absence due to burnout: absentees' experiences. Qual Health Res 2008; 18(5): 620-632.

24 Cimiotti J, Aiken L, Sloan D, Wu E. Nurse staffing, burnout, and health careassociated infection. Am J Infect Control 2012; 40(6): 486-490.

25 Halbesleben J, Wakefield B, Wakefield D, Cooper L. Nurse burnout and patient safety outcomes: nurse safety perception versus reporting behavior. West J Nurs Res 2008; 30(5): 560-577.

26 Leiter M, Harvie P, Frizzell C. The correspondence of patient satisfaction and nurse burnout. Soc Sci Med 1998; 47: 1611-1617.

27 Lake E. Advances in understanding and predicting nurse turnover. Res Sociol Health Care 1998; 15: 147-171.

28 Lombardo B, Eyre C. Compassion fatigue: a nurse's primer. Online J Issues Nurs 2011; 16(1): 3 .

29 Nursing Executive Committee. Reversing the Flight of Talent: Nursing Retention in an Era of Gathering Shortage. Advisory Board: Washington, DC, USA, 2000.

30 Singer L, Fulton S, Kirchner H, Eisengart S, Lewis B, Short E et al. Parenting very low birth weight children at school age: maternal stress and coping. J Pediatr 2007; 151(5): 463-469.

31 Singer L, Salvator A, Guo S, Collin M, Lilien L, Baley J. Maternal psychological distress and parenting stress after the birth of a very low-birth-weight infant. JAMA 1999; 281(9): 799-805.

32 Cho J, Holditch-Davis D, Miles S. Effects of maternal depressive symptoms and infant gender on the interactions between mothers and their medically at-risk infants. J Obstet Gynecol Neonatal Nurs 2008; 37(1): 58-70.

33 Miles S, Holditch-Davis D, Schwartz T, Scher M. Depressive symptoms in mothers of prematurely born infants. J Dev Behav Pediatr 2007; 28(1): 36-44.

34 Segre L, McCabe J, Chuffo-Siewert R, O'Hara M. Depression and anxiety symp toms in mothers of newborns hospitalized on the Neonatal Intensive Care Unit. Nurs Res 2014; 63(5): 320-332.

35 Lefkowitz D, Baxt C, Evans J. Prevalence and correlates of posttraumatic stress and postpartum depression in parents of infants in the Neonatal Intensive Care Unit (NICU). J Clin Psychol Med Settings 2010; 17(3): 230-237.
36 Davis L, Edwards $\mathrm{H}$, Mohay $\mathrm{H}$, Wollin J. The impact of very premature birth on the psychological health of mothers. Early Hum Dev 2003; 73(1-2): 61-70.

37 Rogers $\mathrm{C}$, Kidokoro $\mathrm{H}$, Wallendorf $\mathrm{M}$, Inder T. Identifying mothers of very preterm infants at-risk for postpartum depression and anxiety before discharge. J Perinatol 2013; 33(3): 171-176.

38 Mackley A, Locke R, Speak M, Joseph R. Forgotten parent: NICU paternal emotional response. Adv Neonatal Care 2010; 10(4): 200-203.

39 Shaw R, Bernard R, DeBlois T, Ikuta L, Ginzburg K, Koopman C. The relationship between acute stress disorder and posttraumatic stress disorder in the neonatal intensive care unit. Psychosomatics 2009; 50(2): 131-137.

40 Vanderbilt D, Bushley T, Young R, Frank D. Acute posttraumatic stress symptoms among urban mothers with newborns in the neonatal intensive care unit: a preliminary study. J Dev Behav Pediatr 2009; 30(1): 50-56.

41 DeMier R, Hynan M, Harris H, Manniello R. Perinatal stressors as predictors of symptoms of posttraumatic stress in mothers of infants at high risk. $J$ Perinatol 1996; 16(4): 276-280.

42 Feeley N, Zelkowitz P, Cormier C, Charbonneau L, Lacroix A, Papageorgiou A Posttraumatic stress among mothers of very low birthweight infants at 6 months after discharge from the neonatal intensive care unit. Appl Nurs Res 2011; 24(2): 114-117.

43 Feldman R, Greenbaum C, Oke S, Golding J. Change in mother-infant interactive behavior: relations to change in the mother, the infant, and the social context. Infant Behav Dev 1997; 20(2): 151-163.

44 Bernard-Bonnin A, Psychosocial Paediatrics Committee of Canadian Society of Pediatrics, Canadian Paediatric Society. Maternal depression and child development. Pediatr Child Health 2004; 9(8): 575-583.

45 Huhtala M, Korja R, Lehtonen L, Haataha L, Lapinleimu P, Rautava P et al. Parental psychological well-being and behavioral outcome of very low birth weight infants at 3 years. Pediatrics 2012; 129(4): e937-e944.

46 Segre L, Stasik S, O'Hara M, Arndt S. Listening visits: an evaluation of the effectiveness and acceptability of a home-based depression treatment Psychother Res 2010; 20(6): 712-721.

47 Shaw R, St. John N, Lilo E, Jo B, Benitez W, Stevenson D et al. Prevention of traumatic stress in mothers of preterm infants: a randomized controlled trial. Pediatrics 2013; 132(4): 1-9.

48 Melnyk B, Feinstein N, Alpert-Gillis L, Fairbanks E, Crean H, Sinkin R et al. Reducing premature infants' length of stay and improving parents' mental health outcomes with the Creating Opportunities for Parent Empowerment (COPE) neonatal intensive care unit program: a randomized, controlled trial. Pediatrics 2006; 118(5): e1414-e1427.

49 Harrison T. Family-centered pediatric nursing care: state of the science. J Pediatr Nurs 2010; 25: 335-343.

50 American Academy of Pediatrics, Committee on Hospital Care, Institute for Patient- and Family-Centered Care. Patient- and family-centered care and the pediatrician's role. Pediatrics 2012; 129(2): 394-404

51 The Joint Commission. Advancing Effective Communication, Cultural Competence, and Patient- and Family-Centered Care: A Roadmap for Hospitals. The Join Commission: Oakbrook Terrace, IL, 2010.

52 Levetown M, American Academy of Pediatrics Committee on Bioethics. Communicating with children and families: from everyday interactions to skill in conveying distressing information. Pediatrics 2008; 121 (5): e1441-e1460.

53 American Academy of Pediatrics, Committee on Pediatric Workforce. Culturally effective pediatric care: education and training issues. Pediatrics 1999; 103 (1): 167-170.

54 Guerrero A, Chen J, Inkelas M, Rodriguez H, Ortega A. Racial and ethnic disparities in pediatric experiences of family-centered care. Med Care 2010; 48(4) 388-393.

55 Douglas M, Pierce J, Rosenkoetter M, Pacquiao D, Callister L, Hatter-Pollara M et al. Standards of practice for culturally competent nursing care: 2011 update. J Transcult Nurs 2011; 22(4): 317-333.

56 Weibe A, Young B. Parent perspectives from a neonatal intensive care unit: a missing piece of the culturally congruent care puzzle. J Transcult Nurs 2011; 22 (1): 77-82.

57 Latour J, Hazelzet J, Duivenvoorden H, Goudoever J. Perceptions of parents, nurses, and physicians on neonatal intensive care practices. J Pediatr 2010; 157: 215-220.

58 Ngui E, Flores G. Satisfaction with care and ease of using health care services among parents of children with special health care needs: the roles of race/ ethnicity, insurance, language, and adequacy of family-centered care. Pediatrics 2006; 117(4): 1184-1196.

59 Jones M, Qzai M, Young K. Ethnic differences in parent preference to be present for painful medical procedures. Pediatrics 2005; 116(2): e191-e197.

60 Tang W, Taylor J, Hoehn K, Fuchs L. Trust, mistrust, and communication in the Neonatal Intensive Care Unit [Internet]. Master's thesis, Drexel University School of Public Health, Philadelphia, PA, 2011; available at: https://www.google.com/? 
gws_rd = ssl\#q = tang+master\%27 s+thesis+drexel+university+Trust $\% 2 \mathrm{C}+$ mistrust $\% 2 \mathrm{C}+$ and+communication+in+the+Neonatal+Intensive+Care+Unit (date last accessed 1 April 2015).

61 National Network of Libraries of Medicine. Health Literacy, 2014; available at: http://nnlm.gov/outreach/consumer/hlthlit.html (last accessed on 13 June 2015).

62 US Department of Health and Human Services. The SHARE Approach-Using the Teach-Back Technique: A Reference Guide for Health Care Providers [Internet]. Agency for Healthcare Research and Quality; available at: http://www.ahrq.gov/ professionals/education/curriculum-tools/shareddecisionmaking/tools/tool-6/ index.html (last accessed 29 August 2015).

63 Enlow E, Herbert S, Jovel I, Lorch S, Anderson C, Chamberlain L. Neonatal intensive care unit to home: the transition from parent and pediatrician perspectives, a prospective cohort study. J Perinatol 2014; 34: 761-766.

64 Flores G, Abreu M, Schwartz I, Hill M. The importance of language and culture in pediatric care: case studies from the Latino community. J Pediatr 2000; 137(6): 842-848.

65 Kowalski W, Leef K, Mackley A, Spear M, Paul D. Communicating with parents of premature infants: who is the informant? J Perinatol 2006; 26(1): 44-48.

66 Berns S, Popper B, Gooding J, the Preemie Health Coalition. Results of the premature birth national Need-Gap Study. J Perinatol 2007; 27(Suppl. 2): S38-S44.

67 Mok E, Leung S. Nurses as providers of support for mothers of premature infants. J Clin Nurs 2006; 15: 726-734.

68 Wigert H, Dellenmark M, Bry K. Strengths and weaknesses of parent-staff communication in the NICU: a survey assessment. BMC Pediatr 2013; 13: 71; available at: http://www.biomedcentral.com/1471-2431/13/71 (date last accessed 9 March 2015).

69 De Wit S, Donohue P, Shepard J, Boss R. Mother-clinician discussions in the neonatal intensive care unit: agree to disagree? J Perinatol 2013; 33: 278-281.

70 Boss R, Donohue P, Arnold R. Adolescent mothers in the NICU: how much do they understand? J Perinatol 2010; 30: 286-290.

71 El Sayed M, Chan M, McAllister M, Hellmann J. End-of-life care in Toronto neonatal intensive care units: challenges for physician trainees. Arch Dis Child Fetal Neonatal Ed 2013; 98 (6): F528-F533.

72 Izatt S. Educational perspectives: difficult conversations in the Neonatal Intensive Care Unit. Neoreviews 2008; 9(8): e321-e325.

73 Sharp M, Strauss R, Lorch S. Communicating medical bad news: parents' experiences and preferences. J Pediatr 1992; 121(4): 539-546.

74 Krahn G, Hallum A, Kime C. Are there good ways to give 'bad news'? Pediatrics 1993; 91(3): 578-582.

75 Gallagher K, Cass H, Black R, Norrige M. A training needs analysis of neonatal and paediatric health-care staff in a tertiary children's hospital. Int J Palliat Nurs 2012; 18(4): 197-201.

76 Janvier A, Lantos J, for the POST Investigators. Ethics and etiquette in neonatal intensive care. JAMA Pediatr 2014; 168(9): 857-858.

77 Aagaard H, Hall E. Mothers' experiences of having a preterm infant in the neonatal care unit: a meta-synthesis. J Pediatr Nurs 2008; 23(3): e26-e36.

78 Boss R, Hutton N, Donohue P, Arnold R. Neonatologist training to guide family decision making for critically ill infants. Arch Pediatr Adolesc Med 2009; 163(9): 738-788.

79 National Association of Neonatal Nurses. Palliative and end-of-life care for newborns and infants. Position Statement No. 3063. National Association of Neonatal Nurses, 2015; available at: http://www.nann.org/uploads/files/Palliati veCare6_FINAL.pdf (last accessed 15 April 2015).

80 Cleveland L. Parenting in the neonatal intensive care unit. J Obstet Gynecol Neonatal Nurs 2008; 37: 666-691.

81 Cummings J, American Academy of Pediatrics, Committee on Fetus and Newborn. Antenatal counseling regarding resuscitation and intensive care before 25 Weeks of gestation. Pediatrics 2015; 136(3): 588-595.

82 Stokes T, Watson K, Boss R. Teaching antenatal counseling skills to neonatal providers. Semin Perinatol 2014; 38: 47-51.

83 Biasini A, Fantini F, Neri E, Stella M, Arcangeli T. Communication in the neonatal intensive care unit: a continuous challenge. J Matern Fetal Neonatal Med 2012; 25(10): 2126-2169.

84 Boss R, Urban A, Barnett M, Arnold R. Neonatal critical care communication (NC3): training NICU physicians and nurse practitioners. J Perinatol 2013; 33(8): 642-646.

85 Cone S. The impact of communication and the neonatal intensive care unit environment on parent involvement. Newborn Infant Nurs Rev 2007; 7(1): 33-38.

86 Cuttano A, Scaramuzzo R, Gentile M, Ciantelli M, Sigali E, Boldrini A. Education in neonatology by simulation: between reality and declaration of intent. $J$ Matern Fetal Neonatal Med 2011; 24(S(1)): 97.

87 Meyer E, Brodsky D, Hansen A, Lamiani G, Sellers D, Browning D. An interdisciplinary, family-focused approach to relational learning in neonatal intensive care. J Perinatol 2011; 31: 212-219.

88 Watson K. Serious play: teaching medical skills with improvisational theater techniques. Acad Med 2011; 86(10): 1260-1265.
89 Weis J, Zoffman V, Egerod I. Improved nurse-parent communication in neonatal intensive care unit: evaluation and adjustment of an implementation strategy. J Clin Nurs 2014; 23: 3478-3489.

90 Kruijver I, Kerkstra A, Francke A, Bensing J, van de Wiel H. Evaluation of communication training programs in nursing care: a review of the literature. Patient Educ Couns 2000; 39: 129-145.

91 Koh T, Jarvis C. Promoting effective communication in neonatal intensive care units by audiotaping doctor-parent conversations. Int J Clin Pract 1998; 52(1): 27-29.

92 Penticuff J, Arbeart K. Effectiveness of an intervention to improve parent-professional collaboration in neonatal intensive care. J Perinat Neonat Nurs 2005; 19 (2): 187-202.

93 Johnston A, Bullock C, Graham J, Reilly M, Rocha C, Hoopes R et al. Implementation and case-study results of potentially better practices for familycentered care: the family-centered care map. Pediatrics 2006; 118: 108-114.

94 Weiss S, Goldlust E, Vaucher Y. Improving parent satisfaction: an intervention to increase neonatal parent-provider communication. J Perinatol 2010; 30(6): 425-430.

95 Voos K, Ross G, Ward M, Yohay A, Osorio S, Perlman J. Effects of implementing family-centered rounds (FCR) in a neonatal intensive care unit (NICU). J Matern Fetal Neonatal Med 2012; 24(11): 1403-1406.

96 Erby L, Roter D, Biesecker B. Examination of standardized patient performance: accuracy and consistency of six standardized patients over time. Patient Educ Couns 2011; 85(2): 194-200.

97 Calhoun A, Rider E, Meyer E, Lamiani G, Truog R. Assessment of communication skills and self-appraisal in the simulated environment: feasibility of multirater feedback with gap analysis. Simul Healthc 2009; 4(1): 22-29.

98 Lane C, Rollnick S. The use of simulated patients and role-play in communication skills training: a review of the literature to August 2005. Patient Educ Couns 2007; 67(1-2): 13-20.

99 Segre L, Chuffo-Siewert R, Brock R, O'Hara M. Emotional distress in mothers of preterm hospitalized infants: a feasibility trial of nurse-delivered treatment. J Perinatol 2013; 33: 924-928.

100 Chuffo-Siewert R, Cline M, Segre L. Implementation of an innovative nursedelivered depression intervention for mothers of NICU infants. Adv Neonatal Care 2015; 15(2): 1-8.

101 Toolkit for Professionals. Available at: www.support4nicuparents.org.

102 Mullan B, Kothe E. Evaluating a nursing communication skills training course: the relationships between self-rated ability, satisfaction, and actual performance. Nurse Educ Pract 2010; 10: 374-378.

103 Schirmer J, Mauksch L, Lang F, Marvel K, Zoppi K, Epstein R et al. Assessing communication competence: a review of current tools. Family Med 2005; 37(3): 184-192.

104 Gold K, Dalton V, Schwent T. Hospital care for parents after perinatal death. Obstet Gynecol 2007; 109(5): 1156-1166.

105 Hall $\mathrm{E}$, Kronborg $\mathrm{H}$, Aagaard $\mathrm{H}$, Ammentorp J. Walking the line between the possible and the ideal: lived experiences of neonatal nurses. Intensive Crit Care Nurs 2010; 26: 307-313

106 National Association of Perinatal Social Workers. Standards for Social Work Services in the Newborn Intensive Care Unit. National Association of Perinatal Social Workers, 2007; available at: http://napsw.org/about/pdfs/NICU-standards.pdf (date last accessed 15 April 2015).

107 Caldeira S, Hall J. Spiritual leadership and spiritual care in neonatology. J Nurs Manage 2012; 20: 1069-1075.

108 Russell R. Professional chaplains in comprehensive patient-centered care. $R$ I Med J 2014; 97(3): 39-42.

109 Guthrie M. A health care chaplain's pastoral response to moral distress. J Health Care Chaplain 2014; 20(1): 3-15

110 Funderburk A. Mentoring: the retention factor in the acute care setting. J Nurses Staff Dev 2008; 24(3): E1-E5.

111 Oehler J, Davidson M, Starr L, Lee D. Burnout, job stress, anxiety, and perceived social support in neonatal nurses. Heart Lung 1991; 20 ( Part 1): 500-505.

112 Bilgen H, Topuzoglu A, Kuscu K, Altuncu E, Ozek E. End-of-life decisions in the newborn period: attitudes and practices of doctors and nurses. Turk $J$ Pediatr 2009; 51(3): 248-256.

113 American Academy of Pediatrics, Committee on Fetus and Newborn. Noninitiation or withdrawal of intensive care for high-risk newborns. Pediatrics 2007; 119(2): 401-403.

114 Pignottie M, Donzelli G. Perinatal care at the threshold of viability: an international comparison of practical guidelines for the treatment of extremely preterm births. Pediatrics 2008; 121(1): 193.

115 Aladangady N, de Rooy L. Withholding or withdrawal of life sustaining treatment for newborn infants. Early Hum Dev 2012; 88(2): 65-69.

116 Cortezzo D, Sanders M, Brownell E, Moss K. Neonatologists' perspectives of palliative and end-of-life care in neonatal intensive care units. J Perinatol 2013; 33(9): 731-715. 
117 Kain V. An exploration of the grief experiences of neonatal nurses: a focus group study. J Neonatal Nurs 2013; 19: 80; available from ScienceDirect at: http://www.sciencedirect.com/science/article/pii/S1355184112001093 (last accessed 31 March 2015).

118 White R, Consensus Committee Chairman. Recommended standards for newborn ICU design. J Perinatol 2006; 26: S2-S18.

119 Bosch S, Bledsoe T, Jenzarli A. Staff perceptions before and after adding singlefamily rooms in the NICU. HERD 2012; 5(4): 64-75.

120 Harris D, Shepley M, White R, Kolberg K, Harrell J. The impact of single family room design on patients and staff: executive summary. J Perinatol 2006; 26 S38-S48.

121 Shepley M, Harris D, White R. Open-bay and single-family room neonatal intensive care units: caregiver satisfaction and stress. Environ Behav 2008; 40(2): 249-268.

122 Stevens D, Helseth C, Thompson P, Pottala J, Khan M, Munson D. A comprehensive comparison of open-bay and single-family-room Neonatal Intensive Care Units at Sanford Children's Hospital. HERD 2012; 5(4): 23-39.

123 Walsh W, McCullough K, White R. Room for improvement: nurses' perceptions of providing care in a single room newborn intensive care setting. Adv Neonatal Care 2006; 6(5): 261-270.

124 Rochefort C, Clarke S. Nurses' work environments, care rationing, job outcomes, and quality of care on neonatal units. J Adv Nurs 2010; 66(10): 2213-2224.

125 Kotzer A, Zacharakis S, Raynolds M, Buenning F. Evaluation of the built environment: staff and family satisfaction pre- and post-occupancy of the Children's Hospital. HERD 2011; 4(4): 60-78.

126 White R. Individual rooms in the NICU—an evolving concept. J Perinatol 2003; 23: S22-S24.
127 Pineda R, Stransky K, Rogers C, Duncan M, Smith G, Neil J et al. The single-patient room in the NICU: maternal and family effects. J Perinatol 2012; 32: 545-551.

128 Pineda R, Neil J, Dierker D, Smyser C, Wallendorf M, Kidoro H et al. Alterations in brain structure and neurodevelopmental outcome in preterm infants hospitalized in different neonatal intensive care unit environments. J Pediatr 2014; 164 (1): $52-60$.

129 Montgomery A. The inevitability of physician burnout: implications for interventions. Burnout Res 2014; 1(1): 50-56.

130 National Association of Neonatal Nurses. The Effect of Staff Nurses' Shift Length and Fatigue on Patient Safety, Position Statement No. 3054. National Association of Neonatal Nurses, 2011; available at: http://www.nann.org/uploads/files/The Effect_of_Staff_Nurses_Shift_Length_and_Fatigue_on_Patient_Safety_2011.pdf (date last accessed 15 April 2015).

131 Keeton K, Fenner DE, Johnson TR, Hayward RA. Predictors of physician career satisfaction, work-life balance, and burnout. Obstet Gynecol 2007; 109: 949-955.

132 Cohen-Katz J, Wiley S, Capuano T, Baker D, Shapiro S. The effects of mindfulnessbased stress reduction on nurse stress and burnout: a quantitative and qualitative study. Holist Nurs Pract 2004; 18(6): 302-308.

cC) $($ ) This work is licensed under a Creative Commons Attributioncc) NonCommercial-NoDerivs 4.0 International License. The images or other third party material in this article are included in the article's Creative Commons license, unless indicated otherwise in the credit line; if the material is not included under the Creative Commons license, users will need to obtain permission from the license holder to reproduce the material. To view a copy of this license, visit http:// creativecommons.org/licenses/by-nc-nd/4.0/ 